\title{
Towards a Competence based System for Recommending Study Materials (CBSR)
}

\author{
Athitaya Nitchot, Lester Gilbert, Gary B Wills \\ Learning Society Lab, School of Electronics and Computer Science \\ University of Southampton \\ Southampton, SO17 1BJ, United Kingdom \\ \{an08r, lg3,gbw\}@ecs.soton.ac.uk)
}

\begin{abstract}
Most e-learning systems require intervention from a teacher. The development of adaptive hypermedia systems, such as intelligent tutoring systems, aimed to reduce the teachers' task. However, such systems are still at risk of inconsistently modelling the user when estimating a learner's knowledge level. We propose a system called CBSR (Competence based System for Recommending Study Materials) which recommends appropriate study materials from the Web without requiring teacher intervention, based upon a competency model. This has the benefit of an improved pedagogical approach to e-learning, and a more consistent profile of learners' competences which can persist though their life.
\end{abstract}

Keywords-Competency Model; User Modelling; Adaptive Hypermedia; Web-based Education

\section{INTRODUCTION}

Improving the performance of learning and teaching activities by giving or managing appropriate technological resources from the Web is an increasingly important part of e-learning. Originally intelligent tutoring systems [1] were intended to support such improvements, and these led to the current instantiations of Adaptive Educational Hypermedia (AEH) including user modelling. AEH offers a generated or adapted personalised Web-based application for educational purposes. Normally, adaptive systems use a user model to adapt their content and navigational possibilities to a particular user. However, there are some limitations of user models such as their inconsistency in estimating the level of learners' knowledge [2] and the difficulty of constructing models which adhere to standardized adaptive techniques [3].

The intention of this paper is to introduce an approach for dealing with the problems of user modelling in adaptive educational systems. We illustrate the approach in the design of a system for recommending appropriate study materials from the Web to the learner without any interaction from the teacher. Our system is based on a competency model which supports the lifelong use of the system, gives consistency in recording the learner's level of performance, and is consistent with pedagogical approaches to e-learning systems.

This paper is organized as follows. Section 2 gives the scope and details focusing on $\mathrm{AH}$ and the problems of user modelling. Section 3 introduces the competency model [4] which is used in the proposed system design. Section 4 introduces the system design and the process inside the system. Section 5 presents some conclusions.

\section{ADAPTIVE HYPERMEDIA AND USER MODELS}

\section{A. Adaptive Hypermedia in Educational Perspective}

An Adaptive Hypermedia system (AHS) generates a user model of preferences, knowledge and goals. An AHS tends to improve the usability of hypertext and hypermedia applications by personalizing them based on the constructed user model. Adaptive Hypermedia can generally be implemented in areas where hypermedia is expected to be used by people with different knowledge and goals. One of these areas is the educational domain and this is known as Adaptive Educational Hypermedia (AEH). There are several AEH systems such as InterBook [5], AHA! [6], and ELMART [7].

\section{B. Drawback of Current Methods for User Modelling}

The user model in Adaptive Hypermedia is one of the important components in Adaptive Hypermedia architecture. The user model represents the level of the user's knowledge that affects their learning and performance. The user model generally is either an overlay or a stereotype model [8]. In overlay modelling, the user's state of knowledge is described as a version of the expert's knowledge of the domain. In stereotype modelling users are categorized into stereotypes (such as novice, intermediate, advanced, or expert) or as a member of a group of users that have common characteristic attributes [8].

Kobsa [3] notes that user modelling components mostly draw assumptions about the user which may not necessarily be correct. User modelling therefore inherently involves the risk of misunderstandings, inaccuracies, and inconsistencies [2]. In addition, authoring a user model is difficult since this is a complex task, good models of users are deficient, and there are no standardized approaches to adaptive techniques in the system. Associated with the difficulties of maintaining and updating rules, content, and assessment within the system in an interoperable way, the resulting user model offers poor support for lifelong learning. 
Table 1: Comparison Chart of Adaptive Hypermedia Systems

\begin{tabular}{|c|c|c|c|c|c|}
\hline Features & User Model & & Competency & Feedback & Feedback \\
\hline Systems & & $\begin{array}{l}\text { Prerequisite } \\
\text { (Consider the required } \\
\text { level of learner?) }\end{array}$ & $\begin{array}{l}\text { Support the aspect of capability } \\
\text { of learner in order to achieve } \\
\text { intended learning outcome? }\end{array}$ & $\begin{array}{l}\text { feedback for the } \\
\text { user) }\end{array}$ & $\begin{array}{l}\text { interaction } \\
\text { between teacher } \\
\text { and learner) }\end{array}$ \\
\hline InterBook [5] & Overlay and stereotype & $\begin{array}{l}\text { No } \\
(*)\end{array}$ & No & No & Yes \\
\hline ELM-ART [7] & Overlay and stereotype & $\begin{array}{l}\text { No } \\
(*)\end{array}$ & No & No & No \\
\hline AHA! [6] & Overlay & $\begin{array}{l}\text { No } \\
(*)\end{array}$ & No & No & Yes \\
\hline ADAPTS [9] & $\begin{array}{l}\text { Multi-aspect overlay } \\
\text { user model }\end{array}$ & $\begin{array}{l}\text { No } \\
(*)\end{array}$ & No & Yes & No \\
\hline $\begin{array}{l}\text { Intelligent Tutoring } \\
\text { system [1] }\end{array}$ & Not mentioned & $\begin{array}{l}\text { No } \\
(*)\end{array}$ & No & Yes & No \\
\hline
\end{tabular}

(*) Although not explicitly mentioned in the paper reference, it is likely that this model does not support prerequisite

\section{Comparison of AHS}

Table 1 compares selected AHSs in terms of their support for learner competences and for the provision of learning feedback. It is obvious that none of the systems supports features based on the ability of the learner after he/she learns from these systems. It is also clear that a learner can use the systems without pre-setting of prerequisite or required level of learning. Some systems such as InterBook and AHA! allow interaction from the teacher through feedback. The intelligent tutoring system and ADAPTS give the feedback automatically to the learners.

\section{COMPETENCY MODELLING}

The proposed model for this paper draws on the multidimensional competency model (called COMBA) from Sitthisak, Gilbert and Davis [4] which considers the learners' "learned capability" instead of their "knowledge level" which is difficult to properly characterize or estimate. The COMBA model consists of three major components: subject matter, capability, and context (Figure 1).

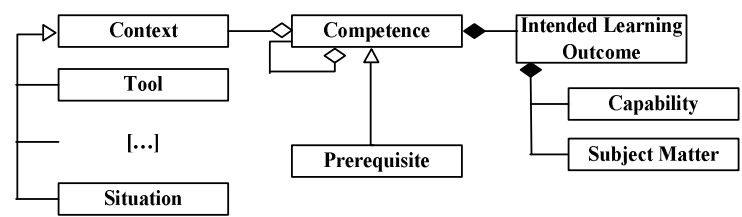

Figure 1: COMBA Competency Model

From Figure 1, it is obvious that the COMBA model incorporates the intended learning outcomes which can be formally described as the composition of 'capability' and 'subject matter'. 'Capability' indicates what the learner will be able to do with the subject matter of the e-learning objectives. Intended learning outcomes indicate the learner's motivation and express the objective of the e-learning [10]. Hence the COMBA model supports the pedagogical approach of the design of an e-learning system. In addition, when coupled with the ability of the competency model to be rendered in an interoperable form, such systems allows the learner to use the system anytime throughout his/her life.

\section{SYSTEM DESIGN FOR CBSR}

This paper considers the design of a system so that a learner can find appropriate study materials on the Web without any interaction from the teacher. The competence model used describes the ability of a learner in certain situations or specific contexts, hence a competence is a method of recording a learner's current abilities and identifying the abilities required.

\section{A. The Consideration of Learner's Competences}

For our system design (CBSR), there are two different types of learner competences: current/existing and desired. The current or existing competence is the estimation of the actual competence of the learner. The desired competence refers to the learner's intended learning outcome or the competence which the learner wishes to gain.

\section{B. The Process within the System}

After the existing and desired competences of the learner are established, Figure 2 illustrates a possible process for deriving recommended study materials.

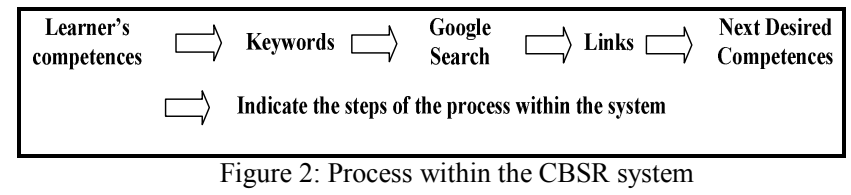

Figure 2 illustrates how a system deals with learners' competences and how it recommends appropriate study materials from the Web to learners. First we consider a subprocess for getting learner's competences so that the system can generate keywords from corresponding competences. At this point, a structure of competences is designed (see part C). The options for desired and existing competences depend on a structure of competences elements. Second, after the keywords are obtained, the system automatically obtains Google (or any other appropriate) search results based on these keywords. The links from the Google search are then suggested to learners. Finally, once a learner retrieves appropriate study materials from the Web (links), the system suggests the next desired competence to the 
learner.

\section{Competences Structure}

Consideration of competence structure is essential in order to specify the range of competence elements/nodes for a particular knowledge domain. This highlights the relationship between competence nodes and the gap between desired and existing competence. We consider a sample of a knowledge domain (mathematical factors, common factors, and highest common factors). Table 2 shows a list of competency numbers with corresponding capability and subject matter content.

Table 2: Lists of competencies

\begin{tabular}{|c|l|l|}
\hline Competency Number & Capability & \multicolumn{1}{|c|}{ Subject Matter Content } \\
\hline C01 & Evaluate & Highest Common Factor \\
\hline C02 & Evaluate & Common Factor \\
\hline C03 & Evaluate & Factor \\
\hline C11 & Calculate & Highest Common Factor \\
\hline C12 & Calculate & Common Factor \\
\hline C13 & Calculate & Factor \\
\hline C21 & Define & Highest Common Factor \\
\hline C22 & Define & Common Factor \\
\hline C23 & Define & Factor \\
\hline
\end{tabular}

From the list of competencies in Table 2, we structure these elements into a directed acyclic graph (DAG) representation (Figure 3).

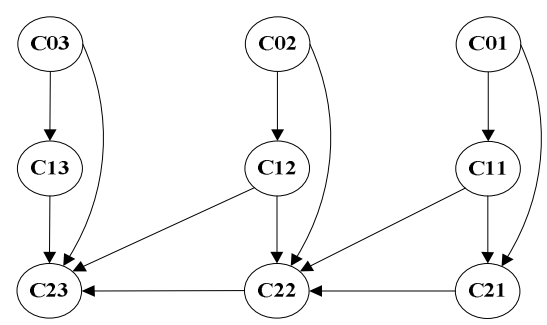

Figure 3: DAG representation for competencies in H.C.F., Common Factor and Factorization domains

At the beginning of the system process, the list of desired competences is provided for learners to choose from, followed by the list of corresponding existing competences. The list of corresponding existing competences refers to children nodes (including children of children nodes) of the desired competence. The system then generates the search terms from the selected learner competences. There are many possibilities for implementing this process. One possibility is to find the gap between desired and existing competence (the route from desired to existing competence) as may be seen from the competence structure (Figure 3). In this case, search terms are considered based on the gap in competences. A learner may need to learn some nodes in a gap before reaching a desired competence. Another possibility is to set a desired competence (capability with subject matter) as the search terms and to then filter these terms using existing competences. The filtering technique could operate by using Google search symbols "+" and "-". The system could generate finalized search terms by adding a "+" symbol in front of every word from the desired competence and adding a "-" symbol in front of every word from the existing competence statement.

The consideration of these possibilities is part of our future work. Our intention in this paper is not to describe the final design of our system, but to introduce the concept of finding appropriate study materials from the Web based on intended learning outcomes, that is, using desired competences informed by existing competences.

\section{CONCLUSION}

We have explored a design for a system for recommending appropriate study materials from the Web to the learner without any communication from a teacher. The design conceptualises two main approaches. First is the reduction of the teacher's task in an e-learning system. Second is addressing the problem in AHS of a user model which is inconsistent in estimating a learner's knowledge level, has no standards for interoperability, and is not generally able to support lifelong learning. The resulting design involves the COMBA competency model which gives the benefit of consistency with pedagogical approaches within e-learning systems.

\section{REFERENCES}

W. F. Contreras, E. G. Galindo, E. M. Caballero, and G. M. Caballero, "An intelligent tutoring system for education by web," in Proceedings of the sixth conference on IASTED International Conference Web-Based Education - Volume 2 Chamonix, France: ACTA Press, 2007.

O. Sitthisak, L. Gilbert, and H. C. Davis, "Towards a competency model for adaptive assessment to support lifelong learning," in TENCompetence Workshop on Service Oriented Approaches and Lifelong Competence Development Infrastructures Manchester, UK, 2007.

A. Kobsa, "User modeling: Recent work, prospects and Hazards.," Adaptive User Interfaces: Principles and Practise, 1993.

O. Sitthisak, L. Gilbert, and H. Davis, "TRANSFORMING A COMPETENCY MODEL TO ASSESSMENT ITEMS " in 4th International Conference on Web Information Systems and Technologies (WEBIST) Funchal, Madeira - Portugal, 2008.

[5] P. Brusilovsky, J. Eklund, and E. Schwarz, "Web-based education for all: a tool for development adaptive courseware," Computer Networks and ISDN Systems, vol. 30, pp. 291-300, 1998.

[6] P. D. Bra, A. Aerts, B. Berden, B. d. Lange, B. Rousseau, T. Santic, D. Smits, and N. Stash, "AHA! The adaptive hypermedia architecture," in Proceedings of the fourteenth ACM conference on Hypertext and hypermedia Nottingham, UK: ACM, 2003.

[7] P. Brusilovsky, E. W. Schwarz, and G. Weber, "ELM-ART: An Intelligent Tutoring System on World Wide Web," in Proceedings of the Third International Conference on Intelligent Tutoring Systems: Springer-Verlag, 1996.

[8] M. Cannataro and A. Pugliese, "A survey of architectures for adaptive hypermedia," in Web Dynamics M. Levene and A. Poulovassilis, Eds., 2004.

[9] P. Brusilovsky and D. W. Cooper, "ADAPTS: Adaptive hypermedia for a Web-based performance support system," in Second Workshop on Adaptive Systems and User Modeling on the World Wide Web, Toronto, Canada, 1999.

[10] L. Gilbert and V. Gale, Principles of E-learning Systems Engineering. Oxford, UK: Chandos Publishing, 2008. 